\title{
Levantamiento del inventario de arte sacro, objetos destinados al culto y otras expresiones artísticas de la Arquidiócesis de San José, 2007 - 2014
}

\section{Luis Carlos Bonilla-Soto ${ }^{I}$ \& Luis Gerardo Santamaría-Rivera $(\text { OFM })^{2}$}

1. Docente en el Seminario Nacional Nuestra Señora de los Ángeles y en la Cátedra de Sociología. Universidad Estatal a Distancia. Costa Rica. lcbonillasoto@gmail.com

2. Licenciado en Artes Plásticas, con énfasis en pintura, por la Universidad de Costa Rica. Fraile menor franciscano (OFM). Perito en el Departamento de Arte Sacro de la Curia Metropolitana de San José. Docente en la Sección de Arte de la Escuela de Estudios Generales. Universidad de Costa Rica. Costa Rica. fraysantamaria@gmail.com

Recibido: 13 de octubre, 2015 • Aceptado: 28 de junio, $2016 \quad$ • Corregido: 12 de agosto, 2016

\section{RESUMEN}

(Find the abstracts in English and French at the end of the article)

El artículo aborda el soporte teórico y la metodología empleada en el levantamiento del inventario de arte sacro, objetos destinados al culto y otras expresiones artísticas de la Arquidiócesis de San José, llevado a cabo entre los años 2007 y 2014. En él se explica la construcción de las categorías de análisis, las opciones investigativas durante el proceso, las dificultades enfrentadas, así como datos puntuales, para ejemplificar la información recopilada y que puede ser utilizada en el estudio de la historia material de la Iglesia en Costa Rica.

Palabras clave: arte sacro - Arquidiócesis de San José - Iglesia costarricense - inventarios - bienes culturales.

\section{Formato de citación según APA}

Bonilla-Soto, L.C. y Santamaría-Rivera, L.G. (2016). Levantamiento del inventario de arte sacro, objetos destinados al culto y otras expresiones artísticas de la Arquidiócesis de San José. 2007-2014. Revista Espiga. Vol. XV, (32), 103-118.

\section{Formato de citación según Chicago}

Bonilla-Soto, Luis Carlos y Luis Gerardo Santamaría-Rivera. «Levantamiento del inventario de arte sacro, objetos destinados al culto y otras expresiones artísticas de la Arquidiócesis de San José». Revista Espiga. XV. N. 32 (2016): 103-118. 
Que en adelante se dé al mantenimiento y restauración de obras de arte religioso (imágenes, pinturas, esculturas y edificaciones) toda la importancia que merecen, que se asignen fondos para ello y se vele cuidadosamente para que todo se haga con estricto apego a las normas que rigen tan delicada materia.

V Sínodo Arquidiocesano, 1985, Nº 196.

\section{Importancia y función de los inventarios en la conservación de la cultura material de la Iglesia}

Cuando las personas que habitan Costa Rica piensan en la Iglesia Católica, uno de los primeros aspectos a los que se dirige su mente es hacia los templos o iglesias (en el lenguaje litúrgico). Es decir, esos recintos que, desde la visión cristiana, se disponen a las colectividades y a los individuos para entrar y centrarse en una experiencia de Dios.

Este direccionamiento mental, en cuanto a las iglesias, posibilita mirar en retrospectiva y determinar cómo las experiencias de lo religioso en los asentamientos humanos de las distintas zonas del país, después de la conquista española, generaron espacios cristianizados para la oración pública y privada, en los cuales los creyentes se valieron de las expresiones simbólicas que evidencian el vínculo entre lo humano y lo divino, así como de diversos acontecimientos de la historia de la salvación, para plasmar pinturas, relieves, mosaicos y esculturas y, de este modo, dejar constancia de sus experiencias y creencias.

Se puede afirmar que las edificaciones cultuales materializan los modos de pensar, vivir, definir, celebrar, compartir o negar las costumbres de los pueblos y, a su vez, condicionan en gran medida los sitios y los objetos asociados a las distintas acciones cotidianas y extra-cotidianas en la dinámica religiosa, llegando a ser el culto católico en el territorio costarricense un acervo rico en este tipo de expresiones plásticas.

La Iglesia, en su magisterio universal, ha dejado patente la relevancia de los bienes culturales que, en el caminar de las distintas y múltiples comunidades de fe, se han creado a lo largo de los siglos. Esta importancia se vuelve evidente en la creación artística:

Entre las actividades más nobles del ingenio humano se cuentan, con razón, las bellas artes, principalmente el arte religioso y su cumbre, que es el arte sacro.

Estas, por su naturaleza, están relacionadas con la infinita belleza de Dios, que intentan expresar de alguna manera por medio de obras humanas. Y tanto más pueden dedicarse a Dios y contribuir a su alabanza y a su gloria cuanto más lejos están de todo propósito que no sea colaborar lo más posible con sus obras para orientar santamente los hombres hacia Dios. (Sacrosanctum Concilium, N. ${ }^{\circ} 122$ )

La actividad artística se ve reflejada de manera determinante en la cultura material de los pueblos de herencia católica, por lo que es posible afirmar que todos los objetos cultuales (o destinados al culto), situados en las iglesias vienen a formar parte del patrimonio cultural de cada diócesis. 
Este patrimonio comprende los bienes muebles que "son los objetos culturales que pueden ser desplazados, trasladados o movidos de un punto a otro, sin menos cabo del inmueble al que estuvieron unidos" (INAH, 2007: 10) así como los bienes inmuebles que acompañan las edificaciones adhiriéndolos al suelo, como sucede con retablos, altares, púlpitos, fuentes, vitrales, puertas o murales.

La Iglesia Católica, en una línea afín a la trazada por organismos internacionales como UNESCO, el Consejo Internacional de Museos (ICOM) e Interpol con el uso del instrumento Object $I D^{1}$, ha insistido en la importancia de proteger los objetos patrimoniales que dan muestra de la historia y de la fe de las múltiples tradiciones católicas, por medio de la realización de inventarios y catálogos para identificar cada uno de los objetos de valor patrimonial.

La importancia de la elaboración de inventarios radica en que este es un mecanismo para el conocimiento, la salvaguarda, la investigación y la divulgación del patrimonio cultural. Además, cada ficha de inventario registrada es un insumo valioso para poder trabajar con los objetos, pues con ella se puede revisar su historicidad, tanto en la información que da cuenta de su origen como de las intervenciones y restauraciones que se han aplicado. La ficha permite identificar los usos que tuvo y tiene cada objeto y da la posibilidad de organizarlos dentro de proyectos de conservación preventiva, con miras a priorizar y determinar necesidades.

Asimismo, muchos bienes de las iglesias como vasos sagrados, crucifijos, imágenes de la virgen María, de santos y santas, ornamentos sacerdotales y muchos otros tantos objetos han sido arrebatados de estos sitios, privando a las nuevas generaciones de la herencia que dejaron las comunidades cristianas a lo largo de los siglos. Igualmente este despojo se da con el agravante de que, cuando no se tienen datos verificables de respaldo de la propiedad eclesial sobre el objeto, su recuperación es casi imposible. Por el contrario, cuando existen fotografías minuciosas, información sobre medidas, peso, estilos, autorías y descripciones de las piezas, se facilita su denuncia y se agiliza su recuperación.

Debido a lo anterior, en relación con la importancia de la ficha de registro de inventario Object ID, en el sitio web del ICOM (s.f.), se expone la relevancia de este tipo de instrumento cuando se afirma:

El comercio ilícito de objetos artísticos está generalmente considerado como una de las formas más frecuentes del crimen internacional.

No hay duda de que la documentación es un elemento crucial para la protección de los objetos culturales robados, como lo demuestra el hecho de que si no existen descripciones ni fotografías raramente pueden ser recobrados. Desgraciadamente, son muy pocos los objetos que cuentan con una descripción suficientemente precisa como para facilitar su recuperación en caso de robo.

Incluso cuando los objetos están documentados, la información acumulada puede variar muchísimo. Es importante, por lo tanto, hacer todo lo posible para que el público vea la necesidad de describir los objetos de modo adecuado y sistemático.

1. Es el instrumento estándar internacional para la descripción de obras de arte, antigüedades y artefactos arqueológicos. 
En el Inventario de arte sacro, objetos destinados al culto y otras expresiones artísticas de la Arquidiócesis de San José se contemplaron los datos estándares empleados para identificar bienes culturales en todo el mundo tal como lo condensa la Object ID. No obstante, para tener mayor claridad conceptual en el momento de redactar el tesauro de dicho inventario, los objetos a considerar dentro del registro fueron pensados en tres categorías, a saber: 1 . Arte sacro, 2. Objetos destinados al culto y 3. Otras expresiones artísticas. A continuación se define cada una de las categorías:

1. Arte sacro: La constitución sobre la Sagrada Liturgia Sacrosanctum Concilium tal como se anotó en la cita previa, realiza una distinción entre el arte sacro y el arte religioso, siendo el primero la cumbre entre ambos. Este se encuentra asociado a la acción litúrgica y, por ende, a la celebración del Misterio de Cristo, es decir, el arte sacro tiene la capacidad de "soportar el peso del misterio mismo, el temor reverencial, la reverencia y asombro que expresa la acción litúrgica" (Conferencia Episcopal Estadounidense, 1978: N. $\left.{ }^{\circ} 21\right)$.

La ambigüedad que ha implicado el concepto de arte sacro, por el hecho de que todo arte religioso cristiano ha sido agrupado, desde el sentido común, por esta terminología, es que se distinguen los otros objetos destinados al culto y otras expresiones artísticas propiedad de la Iglesia. Por ejemplo, una escultura que tenga por temática al Sagrado Corazón de Jesús, en sí misma es una obra de arte religioso, sin embargo, esta llegará a ser arte sacro sólo cuando haya sido incorporada en el culto litúrgico de la Iglesia; en virtud de lo anterior, no es lo mismo una imagen de Jesucristo instalada en un monumento conmemorativo a una empleada en la acción ritual, pues a la segunda la determina el aur $^{2}$ de lo sagrado. De la misma manera, no es lo mismo una obra de arte esculpida y policromada, por maestros imagineros, a una copia de la misma. Para ilustrar lo anterior tenemos el caso de la imagen del Dulce Nombre de Jesús venerada en la iglesia El Carmen de San José, la cual es una obra de arte debido a las calidades de quien la esculpiera en madera de bulto redondo, mas no lo es la copia que de esta se realizara para la iglesia filial del Dulce Nombre de Jesús en el caserío La Florida en el distrito de Hatillo en San José.

2. Objetos destinados al culto: abarca la imaginería, vasos sagrados, objetos que son de uso litúrgico, pero no cumplen los criterios para ser determinados como arte. Sin embargo, al estar incorporados en el espacio litúrgico y al ser empleados en las acciones rituales adquieren el rango de sagrados. Entre estos, se encuentran bienes que no fueron pensados como obras artísticas, pero sí para su uso ritual (muchos con importancia histórica por sus años de existencia) y otros que son bienes fabricados en serie con fines comerciales, pero que han entrado a formar parte del acervo de bienes empleados en el culto, muchos de ellos como vasos sagrados y otros como lo que se ha denominado "artes decorativas". Este tipo de objetos ha ingresado de manera abundante en los últimos tiempos, incluso desplazando objetos de gran valor histórico, pues en la mentalidad de las personas encargadas o benefactoras de las iglesias, lo nuevo es considerado como lo mejor para agradar a Dios.

2. Para entender y profundizar en este concepto basta remitirnos al planteamiento realizado por Walter Benjamin en su obra "La obra de arte en la época de su reproductibilidad técnica". 
3. Otras expresiones artísticas: dentro de esta categoría, se agrupan obras artísticas que pueden contener temática religiosa o no, que son propiedad de las Temporalidades de la Arquidiócesis de San José, pero al no estar ligadas a las acciones sagradas no se pueden catalogar como arte sacro. Asimismo, esta categoría implica aquellos objetos que fueron enajenados de su uso ritual y han adquirido otros usos, tal es el caso de esculturas que sirven como decoración de espacios no religiosos. Ejemplo de esto lo tenemos en los retratos escultóricos y pictóricos de distintos obispos y personajes eclesiásticos, así como monumentos en jardines.

El universo de objetos que comprenden estas tres definiciones se ve materializado en una vasta categoría de objetos, como lo son: esculturas confeccionadas con distintos materiales, pinturas en distintos soportes (muro seco, lienzo), mosaicos, instrumentos musicales, lienzos o telas, orfebrería, artes decorativas, entre otros. De allí que, por facilidad de registro in situ y manejo de los datos en la base prevista para albergarlos, se hayan tipificado seis grupos de objetos: A. Lienzos y ornamentos; B. Imágenes; C. Vasos sagrados y objetos empleados en el culto; D. Libros y documentos; E. Instrumentos musicales; F. Arte no cultual.

\section{Terrenos explorados e inexplorados en la Arquidiócesis de San José}

Este artículo, al tener como fin la descripción de las distintas etapas del Inventario de arte sacro, objetos destinados al culto y otras expresiones artísticas de la Arquidiócesis de San José, como un proceso investigativo que busca contabilizar y conocer más a fondo los bienes culturales eclesiásticos, requiere de algunas referencias que den cuenta de los antecedentes que dieron soporte al proyecto, con miras a clarificar los avances que se realizaron en la materia y precisar cuáles fueron las razones por las que los intentos previos de realizar el inventario general no se habían logrado cabalmente.

Como se señaló en la introducción, los edificios eclesiásticos y los bienes muebles que en ellos se han ido albergando, permiten describir y comprender el desarrollo del catolicismo en estos territorios. De allí que, con el fin de conocer, organizar y proteger, esos bienes que con el tiempo se han constituido en un vasto patrimonio cultural material de la Iglesia, distintas instancias pastorales y administrativas han venido insistiendo en el levantamiento riguroso de los inventarios de bienes culturales eclesiásticos, que incluyen arte sacro, arte religioso y otros objetos artísticos, así como colecciones temáticas que hablan de distintos estadios que han vivido las comunidades de fe.

Tal es el caso de la Pontificia Comisión para los Bienes Culturales de la Iglesia, la cual el 8 de diciembre de 1999, emitió la carta circular Necesidad y urgencia de inventariar y catalogar los bienes culturales de la Iglesia, firmada por el cardenal Francesco Marchisano, presidente de dicha comisión encargada de velar por esta materia en toda la Iglesia Universal. Dicho documento fue dirigido a todos los ordinarios (obispos) de las Iglesias particulares (diócesis) del mundo y en él se hace un llamado contundente a realizar este proceso técnico que da la posibilidad de conocer la existencia y estado de las obras artísticas e históricas que están bajo el cuidado de las diócesis, parroquias, institutos religiosos, 
congregaciones y demás organismos eclesiales. A este documento antecede la circular Opera Artis, emitida por la Sagrada Congregación para el Clero el 11 de abril de 1971, la cual exige la confección de inventarios en donde aparezca la información detallada de los objetos importantes por arte o historia.

En el contexto nacional, aproximadamente hace veinte años, el 5 de julio de 1995, desde la Vicaría Episcopal de Pastoral Profética-Litúrgica se envió, a todos los sacerdotes arquidiocesanos, una comunicación indicando que en cada parroquia se debían realizar las fases eurística (individuación de cada uno de los bienes culturales a inventariar) y analítica (identificación por medio del nombre, autor, técnicas, materiales, medidas, fotografías, condición jurídica, estado e integridad, descripción e información bibliográfica complementaria de cada uno de los bienes) para el levantamiento general del inventario arquidiocesano, quedando en manos del Departamento de arte y ambientación litúrgica, la tercera fase de síntesis, la cual consistiría en la confección de un catálogo, pero este proceso no llegó a feliz término, pues las parroquias no remitieron ninguna información.

Se realizaron procesos de inventario variados y desde distintas instancias. Algunos liderados desde el Ministerio de Cultura, Juventud y Deportes, uno de ellos se realizó en las iglesias de La Merced, El Carmen y la Catedral Metropolitana en San José. Las fichas las levantó Mercedes Fontana, quien fichó algunos objetos. Estas fichas, luego de varios años de extravío aparecieron en la parroquia de San Vicente Ferrer de Moravia y fueron trasladas al Archivo Histórico Arquidiocesano Monseñor Bernardo Augusto Thiel.

Otro inventario, impulsado por este organismo gubernamental, lleva por nombre Inventario de vitrales de los templos católicos de las provincias de San José y Heredia, el cual fue entregado a las autoridades curiales en el año 2006.

Entre otras iniciativas de confeccionar procesos de inventario, se encuentra la realizada por la profesora Anabelle Castro, en los cursos de apreciación de arte latinoamericano en la Escuela de Estudios Generales de la Universidad de Costa Rica, quien de manera coordinada con la Curia y distintas parroquias en el país realizó las fichas de los bienes de los templos. Esta asignación partió del modelo de fichas de inventario, propuestas por Fray Luis Gerardo Santamaría Rivera en sus tesis de licenciatura en Artes Plásticas denominada Inventario de arte religioso en la Arquidiócesis de San José: catálogo.

Como resultado de los diferentes procesos de confección de inventarios, realizados de modo disperso o de manera muy puntual, se emitió el Comunicado sobre el inventario de piezas de arte sacro y demás objetos artísticos de la Arquidiócesis de San José, (16 de julio de 2007) para indicar la importancia de realizar un levantado completo sobre cada una de las obras u objetos de valor artístico tanto cultual como no cultual, y de esta manera generar acciones concretas que permitieran el cuido y manejo adecuado de los bienes artísticos, así como la divulgación y protección de los mismos, en una época en la que los delitos contra la propiedad de la Iglesia han incrementado y el mercado negro de arte sacro crece (UNESCO, 1970: 1).

\section{Inicio del proyecto}

Con el comunicado anteriormente mencionado, emitido por el arzobispo emérito, monseñor Hugo Barrantes Ureña, se inició en agosto de 2007 la visita a los recintos 
propiedad de la Arquidiócesis de san José, siguiendo el orden de la segunda ronda de visitas pastorales que él como pastor de esta Iglesia particular realizó a partir de ese año.

Como objetivo general se estableció el siguiente: "Ordenar los registros de Arte Sacro para el culto de la Arquidiócesis de San José, protegiendo así el patrimonio eclesial arquidiocesano referente a arte sacro y otras propiedades contra hurtos u otras acciones ilícitas, así como del descuido o la impericia de los responsables delegados de su cuidado".

Para poder individualizar cada uno de los objetos y los conjuntos en los que estos se enmarcan, se discutieron y determinaron siete criterios de selección, a saber:

1. Antigüedad:

Todo objeto que tenga más de cincuenta años de existencia.

2. Delicadeza, belleza y materiales con que se elaboró la pieza:

Este criterio atiende al numeral 124 de la Constitución Conciliar Sacro Sacrosanctum Concilium del Vaticano II, que prescribe excluir todo aquello que "repugne a la fe, a las costumbres y a la piedad cristiana y ofendan el sentido auténticamente religioso, ya sea por la depravación de las formas, ya sea por la insuficiencia, la mediocridad o la falsedad del arte."

3. Uso sagrado que tiene o ha tenido el objeto:

Objetos que forman, o formaron en otro momento, parte de algún espacio sagrado.

4. Procedencia y autoría:

Talleres, artistas, artesanos u otras personas destacadas que participaron en la confección de la obra.

5. Rareza:

Objetos excepcionales que es inusual hallarlos en los espacios eclesiásticos.

6. Asociación a otros objetos:

Objetos que forman parte de conjuntos mayores, pero que no están adheridos a la pieza principal. Pueden ser parte aún de la totalidad del conjunto o ser un vestigio de un conjunto en el que la parte principal es ahora inexistente.

7. Tradición y piedad del pueblo creyente.

Todos aquellos bienes que son un referente fundamental en la identidad de cada pueblo, por ser imprescindibles en la realización de acciones rituales o actos de fervor personal que se efectúan de manera generalizada en un lugar.

Sobre este último criterio, se debe señalar que, al poner en diálogo el planteamiento del Concilio Vaticano II y las categorías de objetos para el levantamiento del inventario en cuestión, fue indiscutible la necesidad de considerar la piedad popular y los usos 
rituales en los que los bienes mismos se insertan, no como algo marginal o meramente referencial, sino como parte consustancial de la manufactura de los objetos.

Lo anterior es relevante, ya que, por lo general, cuando se piensa y analiza la piedad popular asociada a las expresiones artísticas se pueden correr varios riesgos, por un lado verla despreciativamente y definirla como una acción dispensable o verla como algo dado en la que no amerita profundizar para entender las obras plásticas.

Por consiguiente, la aprehensión y comprensión de las condiciones de pensamiento, de acción y emoción en las que se confeccionaron los objetos inventariados fueron fundamentales en el momento de realizar el levantamiento de datos, pues se ha considerado justo recopilar la información de cada objeto de manera objetiva sin reducirla a cuestiones formales que niegan la posibilidad de lo trascendente que subyace a los objetos mismos.

\section{Organización de los objetos}

Al ingresar a los distintos recintos -en la mayoría de los casos- los objetos se encontraban dispersos o se hallaban ordenados de modo funcional a las personas que los administraban, cuidaban o utilizaban en ese momento. Por esta razón, una vez que se ingresaba a cada una de las parroquias, se establecía el recorrido por las distintas infraestructuras dentro de ellas, se indagaba y determinaba cada uno de los objetos existentes. Por esta razón se consultaba a las personas encargadas y otras, a quienes ellas nos dirigieran, con miras a recopilar datos referentes a los bienes y pueblos a los que fueron destinados.

Como el fin primordial fue realizar un barrido completo de todos los bienes que cumplieran con los criterios que permitieran determinar si se trataba de arte sacro, objetos destinados al culto u otras expresiones artísticas, se estableció un listado inicial ${ }^{3}$ de códigos para grupos de objetos distribuidos de la siguiente manera:

La categoría A corresponde a lienzos y ornamentos sagrados, en esta se incorporaron los siguientes tipos de objetos existentes en los lugares visitados.

A.01-Corporal / A.02-Purificador / A.03-Palia / A.04-Palio / A.05-Conopeo / A.06Alba o roquete / A.07-Amito / A.08-Cíngulo / A.09-Estola / A.10-Casulla / A.11Manípulo / A.12-Capa pluvial / A.13-Humeral / A.14-Dalmática / A.15-Gremial / A.16-Mitra / A.17-Tunicela / A.18-Velo de Sagrario / A.19-Manteles y frontales / A.20-Otros lienzos.

La categoría B corresponde a imágenes, es decir, toda representación visual o plástica que busque dar cuenta de la Divinidad, de la creación, de la Iglesia y acontecimientos de la historia de la salvación. En esta categoría, los soportes pueden ser de muy distinta índole. Entre estos se encuentran:

3. Se inició de este modo, con el fin de incorporar nuevos códigos según se dieran los hallazgos. 
B.01-Crucifijo / B.02-Nazareno / B.03-Santo Sepulcro / B.04-Cristo yacente / B.05Otra imagen de Jesús / B.06- Imagen mariana / B.07-Ángel / B.08-Imagen de santo(a) (s) / B.09-Vía crucis / B.10-Vitral / B.11-Pintura / B.12-Escultura no especificada / B.13-Pesebre o Belén / B.14-Personaje bíblico / B.15-Animal / B.16-Resucitado / B.17-Cruz / B.18-Mosaico / B.19-Santísima Trinidad / B.20-Bajo Relieve

La categoría $\mathbf{C}$ corresponde a todos los vasos sagrados y los objetos utilizados en las acciones rituales y en actos de piedad popular. Se enlistaron los siguientes:

C.01-Altar mayor adosado a la pared (o altar preconciliar) / C.02-Altar lateral / C.03-Retablo del altar / C.04-Altar / C.05-Púlpito / C.06-Ambón / C.07-Pila bautismal / C.08-Sede / C.09-Pila de agua bendita / C.10-Confesionario / C.11-Credencia / C.12-Campana / C.13-Cruz procesional / C.14-Ciriales / C.15-Cáliz / C.16-Copón / C.17-Patena / C.18-Incensario o turíbulo / C.19-Naveta / C.20-Custodia / C.21-Hisopo / C.22-Caldereta o acetre / C.23-Crismeras / C.24-Viril o lúnula / C.25-Candelabro / C.26-Campanillas o matraca / C.27-Vinajeras / C.28-Lavabo / C.29-Sagrario / C.30-Sacras / C.31-Piedra Ara / C.32-Floreros y jarrones / C.33-Osculatorio / C.34Palmatoria o portapaz / C.35-Reclinatorio / C.36-Pedestal / C.37-Otro / C.38-Atril / C.39-Corona o cetro / C.40-Resplandor o aureola / C.41-Tercerilla o lámpara del santísimo / C.42-Frontal de Mármol / C.43-Frontal de Metal / C.44-Frontal de Madera / C.45-Guión / C.46-Mampara - Puerta / C.47-Placa Conmemorativa / C.48Báculo / C.49-Relicario / C.50-Píxide o porta viático / C.51-Varales / C.52-Expositor / C.53-Exvotos y medallas / C.54-Rosarios / C.55-Comulgatorio o cancela / C.56Andas / C.57-Silla o banca / C.58-Cruz Pectoral / C.59-Anillo

La categoría $\mathbf{D}$ corresponde a piezas documentales, estas se ficharon también con el fin de poner sobre aviso a los encargados del archivo arquidiocesano para que dirigieran las gestiones necesarias en caso de urgir un traslado a los fondos documentales en su haber. Se detallan a continuación:

D.01-Misal / D.02-Pontifical / D.03-Ceremonial / D.04-Ritual / D.05-Otros libros o documentos / D.06-Fotografía

La categoría E corresponde a los instrumentos musicales. Se detallan a continuación:E.01Órgano tubular tipo mecánico / E.02-Órgano tubular tipo eléctrico neumático / E.03-Órgano tubular tipo neumático / E.04-Armonio / E.05-Otro instrumento / E.06-Órgano electrónico.

La categoría $\mathbf{F}$ corresponde a otras expresiones artísticas halladas. Se detallan a continuación:

F.01-Lítica indígena / F.02-Cerámica indígena / F.03-Jade indígena / F.04-Acuarela / F.05-Óleo / F.06-Lápiz / F.07-Escultura en metal / F.08-Escultura en mármol / F.09Escultura en madera / F.10-Escultura en piedra / F.11-Escultura en otro material / F.12-Grabado / F.13-Mueble de madera / F.14-Artesanía indígena / F.15-Otra Artesanía / F.16-Cubiertos y vajillas / F.17-Otro / F.18-Tiza pastel / F.19-Mascarada / F.20Acrílico / F.21-Lápida u otra placa / F.22-Bajo Relieve / F.23-Joyería / F.24-Plumilla 


\section{Construcción de los códigos de registro}

Con todo lo anterior, se asignó un número único para cada objeto, siguiendo de este modo una categorización que permita ubicar cada objeto, según el sitio en el que se le levantó la ficha de registro de cada uno y según el tipo de bien al que corresponde.

Para facilitar la comprensión de este proceso, se enuncia a continuación, a manera de ejemplo, la construcción del código de registro de un cáliz de monseñor Juan Gaspar StorkWerth situado en la Catedral Metropolitana (Ver ficha ASJ-01-02-03-C-15-4 p. 15).

En el caso de la Catedral el código de todos los bienes allí registrados inicia así:

ASJ-01-02-03

Dicho código se construye en la base de datos de la siguiente manera:

ASJ: Arquidiócesis de San José.

Los tres dígitos identifican el sitio dónde se registró la pieza:

Vicaría foránea - parroquia - filial, dependencia u otro.

Siguiendo el criterio de territorialidad pensado para este proyecto, a partir de la distribución de los límites parroquiales existentes al año 2007, la Catedral Metropolitana y otras dependencias que tienen administración autónoma, han sido agrupadas por facilidad de ubicación, barrido de la información, seguridad y manejo en la base de datos- en los territorios parroquiales existentes a esa fecha.

Según este criterio, los dígitos del código de la Catedral responden a la siguiente ubicación territorial:

01 Vicaría Patriarca San José.

02 Parroquia Nuestra Señora de la Soledad.

Al ser la Catedral una las infraestructuras eclesiales situadas dentro de los lindes de la parroquia La Soledad, se dispone el código conforme a esta lista:

01 Centro Parroquial, La Soledad.

02 Rectoría Templo Votivo al Sagrado Corazón de Jesús.

\section{Catedral Metropolitana.}

04 Casa Arzobispal.

05 Capilla del Palacio Arzobispal.

06 Curia Metropolitana.

Seguidamente, el código se completó con las categorías anotadas en letras y números consecutivos, según la naturaleza del bien. En el caso de la catedral, se levantaron 646 fichas. La vasta mayoría de objetos aparecen individualizados en cada ficha, salvo raras excepciones que, por agilidad del procedimiento, se presentan agrupados en una misma. 


\section{AROUDTOCESIS DE SAN IOSE}

Código: AS]-01-02-03-C-15-4

Nombre del custodio o propietario: Temporalidades de la Arquidiócesis de San José

Inscripción:

Ubicación $\mid$ Vicaría: San José

Parroquia: Parroquia Nuestra Señora de La Soledad

Filial: Catedral Metropolitana

Categoría: Vasos Sagrados y objetos usados en el Culto

objeto: Cáliz

Especificidad: Perteneció al Dr. + Juan Gaspar Stork W.

Materia Prima : Plata y baño de oro

\begin{tabular}{l|l} 
Dimensiones & Largo $(\mathrm{cm}): 0$
\end{tabular}

Ancho $(\mathrm{cm}): 0$

Alto $(\mathrm{cm}): 19$

Diametro $(\mathrm{cm}): 14.5$

Peso $(\mathrm{g}): 0$

Manufactura: Relieves, bruñido

Técnica de decoración: Bruñido

Uso o Función: Contener la Sangre de Cristo.

Procedencia / Autor: Alemania

Epoca: S XX

Estilo: Romanico

Conservación: buena

Adquisición: desconocida

Fotografia:

\begin{tabular}{|l|l|}
\hline Fotografia: & $\begin{array}{c}\text { Fototeca: Fotografia tomada el } 7 \text { de marzo del } \\
\text { 2008; por Luis Carlos Bonilla Soto. }\end{array}$ \\
& \\
& \\
\hline Descripción: & $\begin{array}{l}\text { Este Cáliz perteneció al Dr. Juan Gaspar Stork, Obispo de San José de } \\
\text { Costa Rica. En su base medallones en plata: el niño con los doctores en el }\end{array}$ \\
& templo, el bautismo, el nacimiento, la piedad, la resurrección, la crucifixión. \\
En el nudo y copa, estilizaciones de la naturaleza.
\end{tabular}




\section{Visitas de campo, base de datos y productos de investigación}

A septiembre de 2014, de los 557 lugares visitados, se ha ingresado a la base de datos la información de 205 de ellos, lo que representa el 37\% de los datos levantados in situ.

La inserción en la base de datos ha resultado bastante lenta, debido a lo delicado de la materia y la falta de recurso humano para un avance más fluido. No obstante, todas las fichas aun no subidas a la base de datos, se encuentran en borrador para los usos necesarios que han ido surgiendo, tanto para procesos eclesiásticos a lo interno de la arquidiócesis de San José, como a lo externo, que incluyen instituciones y personas que requieren de información precisa sobre objetos para llevar a cabo investigaciones académicas, exhibiciones de arte y procesos de restauración.

El avance más pausado del ingreso a la base de datos está asociado a su vez a elevada cantidad de registros. Solamente con miras a ilustrar la cantidad de fichas, se puede observar en el cuadro 1, la cantidad de registros generados -según cada categoría- en las treinta iglesias que tienen declaratoria como patrimonio histórico arquitectónico de Costa Rica, que en total suman un total 4520 fichas.

\section{CUADRO 1}

Cantidad de fichas levantadas, según categoría de objetos, iglesias declaradas patrimonio histórico arquitectónico. Costa Rica. 2014.

\begin{tabular}{|c|c|c|c|c|c|c|c|}
\hline $\begin{array}{l}\text { Iglesias declaradas } \\
\text { patrimonio nacional }\end{array}$ & $\begin{array}{c}\text { A. } \\
\text { Lienzos }\end{array}$ & $\begin{array}{c}\text { B. } \\
\text { Imágenes }\end{array}$ & $\begin{array}{c}\text { C. } \\
\text { Vasos y objetos } \\
\text { uso cultual }\end{array}$ & $\begin{array}{c}\text { D. } \\
\text { Libros y } \\
\text { documentos }\end{array}$ & $\begin{array}{c}\text { E. } \\
\text { Instrumentos } \\
\text { Musicales }\end{array}$ & $\begin{array}{c}\text { F. } \\
\text { otras } \\
\text { expresiones arte }\end{array}$ & TOTAL \\
\hline Nuestra Señora del Carmen, S.J. & 74 & 49 & 43 & 1 & 2 & 8 & 177 \\
\hline Nuestra Señora de la Soledad & 23 & 106 & 43 & - & 1 & - & 173 \\
\hline Catedral Metropolitana, S.J. & 151 & 121 & 268 & 4 & 2 & 110 & 656 \\
\hline Nuestra Señora de la Merced, S.J. & 39 & 67 & 98 & - & 1 & 4 & 209 \\
\hline San Cayetano, S.J. & 1 & 40 & 40 & & & & 81 \\
\hline Santa Teresita, B ${ }^{\circ}$ Aranjuez, S.J. & 25 & 57 & 54 & - & 1 & 8 & 145 \\
\hline Nuestra Señora La Dolorosa, S.J. & 141 & 87 & 102 & - & 1 & - & 331 \\
\hline Ntra. Sra. de los Desamparados & 29 & 69 & 88 & 4 & 1 & 12 & 203 \\
\hline San Luis de Tolosa, Aserrí & 29 & 96 & 57 & 6 & - & 6 & 194 \\
\hline San Juan (San Pedro), Rincón Grande & - & 4 & - & 7 & - & - & 11 \\
\hline San Antonio de Padua, Escazú & 1 & 50 & 36 & - & - & 1 & 88 \\
\hline Santa Ana & - & 26 & 56 & 2 & 1 & 1 & 86 \\
\hline Santiago Apóstol, Puriscal & - & 1 & 1 & - & - & - & 2 \\
\hline San Pedro, Pedernal, Puriscal & 5 & 27 & 18 & 1 & - & - & 51 \\
\hline San Isidro, Barbacoas, Puriscal & 7 & 30 & 28 & 1 & 1 & - & 67 \\
\hline Ntra. Sra. de los Ángeles, Piedras N. & - & 24 & 9 & - & 1 & 2 & 36 \\
\hline San Isidro Labrador, Coronado & 86 & 66 & 95 & 10 & 1 & 4 & 262 \\
\hline
\end{tabular}


CUADRO 1 (Continuación)

\begin{tabular}{lccccccc}
\multicolumn{1}{c}{$\begin{array}{c}\text { Iglesias declaradas } \\
\text { patrimonio nacional }\end{array}$} & $\begin{array}{c}\text { A. } \\
\text { Lienzos }\end{array}$ & $\begin{array}{c}\text { B. } \\
\text { Imágenes }\end{array}$ & $\begin{array}{c}\text { C. } \\
\text { Vasos y objetos } \\
\text { uso cultual }\end{array}$ & $\begin{array}{c}\text { D. } \\
\text { Libros y } \\
\text { documentos }\end{array}$ & $\begin{array}{c}\text { E. } \\
\text { Instrumentos } \\
\text { Musicales }\end{array}$ & $\begin{array}{c}\text { F. } \\
\text { otras } \\
\text { expresiones arte }\end{array}$ & TOTAL \\
\hline Ntra. Sra. del Carmen, Goicoechea & 5 & 45 & 52 & - & 1 & - & 103 \\
\hline San Francisco, Calle Blancos & 9 & 29 & 35 & - & - & - & 73 \\
San Juan Bautista, Tibás & 85 & 43 & 59 & 2 & - & 1 & 190 \\
\hline Ntra. Sra. de Guadalupe, Loma L. & 1 & 6 & 9 & 2 & - & - & 18 \\
Ntra. Sra. del Rosario, Desamp. & 2 & 22 & 15 & 2 & - & 2 & 43 \\
\hline Ntra. Sra. de Guadalupe, Toledo & & 7 & 2 & - & - & - & 9 \\
San Diego, La Unión, Cartago & 18 & 42 & 33 & - & - & - & 93 \\
\hline Inmaculada Concepción, Heredia & 123 & 117 & 118 & 22 & 1 & 7 & 388 \\
\hline San Bartolomé Apóstol, Barva & 40 & 62 & 32 & - & - & - & 134 \\
\hline San Rafael Arcángel, Heredia & 3 & 87 & 46 & - & - & 2 & 138 \\
\hline San Pablo Apóstol, Heredia & & 5 & - & - & - & - & 5 \\
\hline Santo Domingo, Heredia & 257 & 137 & 99 & 14 & 1 & 1 & 509 \\
Ntra. Sra. del Carmen, La Castilla & 2 & 27 & 13 & 2 & - & 1 & 45 \\
\hline TOTAL & 1156 & 1549 & 1549 & 80 & 15 & 170 & 4520 \\
\hline
\end{tabular}

Fuente: Elaboración propia.

Cada visita realizada implicó la generación de distintos productos de investigación, además de las fichas propiamente dichas. Unos son los informes preliminares, en los que se describen los principales hallazgos por parroquia y se enuncian recomendaciones para atender los problemas más apremiantes que exponen a graves deterioros o riesgos a las distintas obras. Otros productos de investigación son las crónicas de las visitas o diario de campo que narra, según fechas, lo que se visitó en el recorrido.

\section{A manera de cierre}

Las fichas técnicas generadas para cada objeto, están previstas para ser enriquecidas, corregidas, aclaradas y utilizadas con miras a detectar las necesidades más apremiantes de los bienes, con el fin de alcanzar una conservación idónea, un conocimiento a profundidad de cada colección y objeto, además de servir como insumo primordial para administrar y custodiar el patrimonio que albergan los inmuebles de la Iglesia Particular en San José de Costa Rica.

Ejemplo del potencial de este proyecto se puede observar en el trabajo conjunto y en los aportes recíprocos logrados con instituciones estatales, las cuales tienen por objetivo la conservación, estudio y divulgación del patrimonio en nuestro país. Fruto de dichas vinculaciones fue una exhibición de arte sagrado en el Museo Nacional de Costa Rica, realizada durante el tiempo de Cuaresma del año 2012 con el nombre "Silencio ante el 
Sepulcro", la cual implicó trabajos de consolidación, restauración y montaje museográfico con obras de arte inventariadas en la Arquidiócesis, logrando de este modo que funcionarios públicos y especialistas en la materia intervinieran obras de gran valor artístico e histórico. Además, se han ratificado y generado convenidos de préstamo de esculturas para la realización de pesebres durante la Navidad con el Teatro Nacional de Costa Rica y el Museo de Arte Costarricense.

Por una parte, de algunos recintos de culto, con las debidas autorizaciones eclesiásticas, se reubicaron obras artísticas de gran valor que se hallaban en situaciones de gravísima vulnerabilidad, con el fin de que las mismas fueran restauradas y conservadas de modo adecuado. En virtud de ello, aunque algunas piezas se han traslado a las instalaciones del Archivo Histórico Arquidiocesano Monseñor Bernardo Augusto Thiel, a la Curia Metropolitana o hacia otras parroquias con las condiciones adecuadas para estabilizarlas, el historial de cada obra individualizada, se deja constancia de que los traslados realizados no son una acción de despojo hacia las comunidades, sino un acto de salvaguarda del patrimonio que es parte de toda la Iglesia Particular, pues las acciones están pensadas con miras a evitar más pérdidas de las ocurridas en décadas pasadas en tantas iglesias parroquiales y filiales.

Por otra parte, a las parroquias visitadas se les brindó una serie de recomendaciones, por medio de informes escritos, en los cuales se insistía de manera particular en los trabajos necesarios para la conservación preventiva. Sin embargo, al ser un número considerable de parroquias y bienes inventariados, periódicamente se ha insistido, a las personas encargadas, mantener el contacto con la Curia para la realización de cualquier procedimiento de mejora o intervención de los bienes eclesiásticos y evitar de este modo problemas ulteriores.

El inventario ha sido un proceso metódico, sistemático y riguroso, en el que se ha tenido que revisar con calma cada uno de los pasos trazados. Se revisaron con detalle cada uno de los rincones de las edificaciones visitadas y se recopiló información por medio de distintas personas y de fuentes documentales, para así precisar datos sobre los distintos bienes y, pese a que queda mucho trabajo por realizar en materia de salvaguarda y contención del deterioro y malas prácticas de manejo de colecciones a las que se han visto expuestas las obras por tantos años, el planteamiento de todo el proceso ha permitido determinar y manejar los objetos como marcas que vislumbran el camino recorrido, como productos de la inspiración que da Dios a los seres humanos y como relatores que hablan de la historia y las historias en las distintas realidades parroquiales y de otros organismos de la Arquidiócesis de San José.

\section{ABSTRACT}

\section{Lifting of the inventory of sacred art, objects destined to cult and other artistic expressions of San José archdiocese. 2007-2014}

The article addresses the theoretical framework and the methodology used to lift the inventory of sacred art, objects destined to cult and other artistic expressions of the archdioceses of San José, carried out between 2007 and 2014. The reader finds an explanation for the construction of the categories of analysis, the investigative options during the process, difficulties in the process, as 
well as specific data, to exemplify the collected information so that it can be used in the study of the material history of the church in Costa Rica.

Key words: sacred art, San José Archdioceses, Costa Rican church, inventory, cultural goods

\section{RÉSUMÉ}

\section{Élaboration de l'inventaire d'art sacré, d'objets destinés au culte et d'autres expressions artistiques de l'Archidiocèse de San José. 2007-2014}

Cet article aborde le support théorique et la méthodologie employée dans la réalisation de l'inventaire d'art sacré, d'objets destinés au culte et d'autres expressions artistiques de l'Archidiocèse de San José effectué entre les années 2007 et 2014. Il explique la construction des catégories d'analyse, les options de recherche pendant le processus, les difficultés rencontrées ainsi que les données ponctuelles, pour illustrer l'information collectée qui peut être utilisée dans l'étude de l'histoire matérielle de l'Eglise au Costa Rica.

Mots-clés: art sacré - Archidiocèse de San José - Église costaricienne- inventaires- biens culturels.

\section{Referencias bibliográficas}

Alderoqui, H. (1996). Colecciones privadas y patrimonios públicos. Museos y escuelas: socios para educar.Alderoqui, Silvia (Comp). Barcelona: Paidos: 67-81.

Chang, G. (2004). Patrimonio Cultural: bienes materiales e intangibles que nos identifican. Patrimonio Cultural: diversidad en nuestra creación y herencia. San José: Centro de Investigación y Conservación del Patrimonio Cultural: 9-51.

Conferencia Espiscopal Estadounidense (1978). La ambientación y el arte en el culto católico. Enchiridion. Documentación litúrgica posconciliar. Pardo, Andrés (2000) (Comp). Barcelona: Ed.Regina: 1336-1356.

Congregación para el culto divino y la disciplina de los sacramentos (2002). Directorio sobre la Piedad Popular y la Liturgia. México D.F.: Ediciones Juan de Zumárraga.

Documentos Completos de Vaticano II (1965). Bilbao: El Mensajero del Corazón de Jesús.

ICOM (s.f.) Object ID. Directrices para la descripción de obras de arte, antigüedades y objetos arqueológicos. Recuperado de: http://archives.icom.museum/objectid/why_ span.html

Enríquez, F. (2004). Estrategias para estudiar la comunidad donde vivimos. San José: EUNED.

Eduarte, A (2012) La cirugía de los Cristos Yacentes. MuseoNacional de Costa Rica. Recuperado de: http://www.museocostarica.go.cr/es_cr/en-detalle/la-cirug-a-de-loscristos-yacentes.html?Itemid=115

Méndez, A. (2001). El objeto como portador de información. Gaceta de Museos. No 2324, julio-diciembre. México: INAH: 16-20.

Micó, J. (2004). Liturgia católica. Bogotá: Ed.San Pablo.

Pontificia Comisión para los bienes culturales de la Iglesia. (1999) Necesidad y urgencia del inventario y catalogación de los bienes cultude la Iglesia. Apuntes (julio-diciembre, 
2003). Bogotá: Universidad Javeriana: 61-96. Recuperado de:http://revistas.javeriana.edu.co/index.php/revApuntesArq/article/download/9085/7388.

Pontificia Commissione per i beniculturalidellachiesa ( 8 diciembre, 1999) Letteracircolaresullanecessità e urgenzadell' inventariazione e catalogazionedeibeniculturalidella Chiesa. Recuperado de:http://www.vatican.va/roman_curia/pontifical_commissions/ pcchc/documents/rc_com_pcchc_19991208_catalogazione-beni-culturali_it.html

Santamaría Rivera, L. (1996). Inventario de arte religioso en la Arquidiócesis de San José: catálogo. Trabajo Final de Graduación. Licenciatura en Artes Plásticas con énfasis en Pintura. San José: Universidad de Costa Rica.

UNESCO. (1970). Convención sobre las Medidas que Deben Adoptarse para Prohibir e Impedir la Importación, la Exportación y la Transferencia de Propiedad Ilícitas de Bienes Culturales. Recuperado de: http://portal.unesco.org/es/ ev.phpURL_ID=13039\&URL_DO=DO_TOPIC\&URL_SECTION=201.html

UNESCO (2006) Medidas jurídicas y prácticas contra el tráfico ilícito de bienes culturales. Manual de la UNESCO. París. Sección de Normas Internacionales, División de Patrimonio Cultural.

Sínodo Arquidiocesano. Decretos Sinodales. (1985). Curridabat: Talleres Ludovico. 